\title{
THE DETERMINATION OF TBA-REACTIVE SUBSTANCES AND ALKENALS IN THE PRESENCE OF ANTIOXIDANTS
}

\author{
S. T. BALTHAZARY ${ }^{1}$, H.-P. SALLMANN ${ }^{2}$ and H. FUHRMANN ${ }^{2 *}$ \\ ${ }^{1}$ Department of Veterinary Physiology, Biochemistry, Pharmacology and Toxicology, \\ Faculty of Veterinary Medicine, Sokoine University of Agriculture, P.O. Box 3017, \\ Morogoro, Tanzania; ${ }^{2}$ Institute of Physiological Chemistry, Veterinary School of \\ Hannover, Bünteweg 17, D-30559 Hannover, Germany
}

(Received December 8, 1998; accepted January 28, 1999)

This study investigated the inhibitory efficiency of all-rac- $\alpha$-tocopherol, 2,6ditert-butyl-p-cresole (BHT), and 6-hydroxy-2,5,7,8-tetramethyl-chroman-2-carbonic acid (Trolox ${ }^{\circledR}$ ) on determination of thiobarbituric acid-reactive substances (TBARS) and short-chain alkenals in rat liver homogenates. The concentration of TBARS was measured fluorophotometrically. Aldehydes were determined after derivatization with methylhydrazine by gas chromatography (GLC). The concentrations of alkenals and TBARS in liver homogenates were diminished when antioxidants were present during the sample preparation. It is suggested that in the absence of antioxidants the samples are autoxidized further during the preparative procedures. For the aldehyde determination all-rac- $\alpha$-tocopherol was the most effective antioxidant to reduce the bias due to autoxidation, whereas for TBARS it was Trolox.

Key words: Lipid peroxidation, antioxidant, $\alpha$-tocopherol, Trolox, TBARS, aldehydes, malondialdehyde

In the presence of free radicals, polyunsaturated fatty acids in food, cells, or subcellular fractions are prone to peroxidation. This is the ultimate cause of oxidative rancidity in food (Janero, 1990) and also leads to lipid oxidation products with cytotoxic and genotoxic potencies (Esterbauer, 1993). The assay most widely used for lipid peroxidation is the thiobarbituric acid (TBA) method that measures malondialdehyde (MDA) among the total products reacting with TBA (Janero, 1990). However, the conditions of sample preparation are associated with major problems in the determination of TBA-reactive substances (TBARS) obtained from human and animal tissues, because sample preparation may predispose the lipids inherent in the samples to autoxidative processes leading to an overestimation and therefore to erroneous results (Janero, 1990). Recent ap-

\footnotetext{
${ }^{*}$ Corresponding author [Present address: Institute of Veterinary Physiological Chemistry, Faculty of Veterinary Medicine, University of Leipzig, Semmelweisstr. 4, D-04103 Leipzig, Germany; E-mail: fuhrmann@vetmed.uni-leipzig.de; Fax: (0341) 97 28101]
} 
proaches to the assessment of lipid peroxidation (Janero, 1990) are the direct determinations of MDA and other short-chain carbonyls by HPLC or gas chromatography (GLC).

The aim of this experiment was to investigate the efficiency of $\alpha$-tocopherol, Trolox and BHT towards inhibition of autoxidation occurring during sample preparation for alkenal and TBARS determination. The method used for measurement of TBARS was a standard protocol described earlier (Uchiyama and Mihara, 1978). Alkenals were determined by GLC after derivatization with methylhydrazine (Tamura et al., 1991).

\section{Materials and methods}

Six female Wistar rats (280-295 g) were used in this experiment. They were housed in wire cages and had free access to standard diet and water. The animals were fasted $16 \mathrm{~h}$ before they were sacrificed by decapitation. The livers were excised immediately and placed on ice.

For the determination of TBARS, homogenates were prepared in a ratio of $1.2 \mathrm{~g}$ liver to $15 \mathrm{ml} 1.15 \% \mathrm{KCl}$ by using a Potter Elvehjem homogenizer and stored at $-80{ }^{\circ} \mathrm{C}$ until analysis within two weeks. The test for TBARS was conducted in the presence of equimolar amounts of three antioxidants: $52.8 \mathrm{mg}$ BHT, $60 \mathrm{mg}$ Trolox and $103 \mathrm{mg}$ all-rac- $\alpha$-tocopherol were dissolved in $30 \mathrm{ml}$ ethanol. Furthermore, increasing amounts of all-rac- $\alpha$-tocopherol were tested (515 and $1030 \mathrm{mg}$ in $30 \mathrm{ml}$ ethanol). Each $0.3 \mathrm{ml}$ of these solutions were added to $0.5 \mathrm{ml}$ of the liver homogenate as well as to the standard made from 1,1,3,3-tetraethoxypropane. Ethanol was added to the homogenates of the control without antioxidants. With each individual antioxidant a blank was prepared. There was no difference of the blanks between control (without antioxidant) and the antioxidants tested. The assays were incubated at room temperature for $5 \mathrm{~min}$. For determination of TBARS (Uchiyama and Mihara, 1978), $0.5 \mathrm{ml}$ rat liver homogenate was mixed with $3.0 \mathrm{ml}$ phosphoric acid (1\%) and $1.0 \mathrm{ml}$ TBA $(0.6 \%)$, heated to $100{ }^{\circ} \mathrm{C}$ for $45 \mathrm{~min}$ and then cooled on ice. Four $\mathrm{ml} \mathrm{n}$-butanol was added, thoroughly mixed and centrifuged at $4500 \mathrm{rpm}$ for $10 \mathrm{~min}$. The fluorescence of the upper layer was determined fluorophotometrically at $515 \mathrm{~nm}$ excitation and $565 \mathrm{~nm}$ emission.

In parallel experiments the unsaturated aldehydes were measured after derivatization with methylhydrazine (Tamura et al., 1991). Equimolar amounts of three antioxidants (BHT, Trolox, all-rac- $\alpha$-tocopherol) and also increasing amounts of all-rac- $\alpha$-tocopherol were included in the sample preparation. A blank was prepared for each individual antioxidant and the control. The aldehyde hydrazones were separated by GLC and detected with a thermoionic-specific de- 
tector as described recently (Fuhrmann and Sallmann, 1997), 4-hydroxy-6methylheptenal served as an internal standard. The substance was a generous gift of Prof. G. Bringmann (Institute of Organic Chemistry, University of Würzburg, Germany). Malondialdehyde, pentenal, hexenal, OH-hexenal, heptenal, octenal, nonenal and $\mathrm{OH}-$ nonenal were identified according to their retention times in comparison to authentic standards. The hydroxyalkenals were kindly supplied by Prof. H. Zollner (Department of Biochemistry, University of Graz, Austria). The blanks subtracted accordingly were slightly higher when prepared with all-rac- $\alpha-$ tocopherol and Trolox than with BHT and ethanol only (control).

The means were analysed for significant differences $(p<0.05)$ by the Student-Newman-Keuls test.

\section{Results and discussion}

The TBA assay is the most commonly used method to measure the degree of oxidation in a lipid peroxidation system (Benzie, 1996). Table 1 shows the inhibitory activity of all-rac- $\alpha$-tocopherol, BHT and Trolox towards TBARS and alkenal formation in liver homogenates. Comparing equimolar amounts of the antioxidants used, TBARS generation was most effectively inhibited by Trolox (more than $40 \%$ ) and all-rac- $\alpha$-tocopherol (36\%) in comparison to the control group. BHT showed lower inhibition rates (32\%) than Trolox.

\section{Table 1}

Effect of in vitro addition of antioxidants to liver homogenates on determination of TBARS ( $\mu \mathrm{g}$ MDA-equivalents/g liver), individual and total aldehydes ( $\mu \mathrm{g} / \mathrm{g}$ liver). Means $( \pm \mathrm{SE}, \mathrm{n}=6$ ) within a row having different superscript letters differ significantly at $p<0.05$

\begin{tabular}{lcccccc}
\hline & Control & Trolox & BHT & $\alpha$-Toc. & $5 \mathrm{x} \alpha$-Toc. & $10 \mathrm{x} \alpha$-Toc. \\
\hline TBARS & $21.0 \pm 0.3^{\mathrm{a}}$ & $12.4 \pm 1.3^{\mathrm{c}}$ & $14.2 \pm 1.4^{\mathrm{b}}$ & $13.5 \pm 0.6^{\mathrm{bc}}$ & $10.8 \pm 0.9^{\mathrm{d}}$ & $10.1 \pm 0.2^{\mathrm{d}}$ \\
\hline MDA & $3.8 \pm 0.3^{\mathrm{a}}$ & $3.5 \pm 0.3^{\mathrm{ab}}$ & $3.2 \pm 0.3^{\mathrm{b}}$ & $2.9 \pm 0.1^{\mathrm{c}}$ & $2.0 \pm 0.1^{\mathrm{d}}$ & $1.7 \pm 0.1^{\mathrm{e}}$ \\
Pentenal & $0.4 \pm 0.1^{\mathrm{b}}$ & $0.6 \pm 0.1^{\mathrm{a}}$ & $0.4 \pm 0.1^{\mathrm{c}}$ & $0.3 \pm 0.1^{\mathrm{c}}$ & $0.2 \pm 0.1^{\mathrm{d}}$ & $0.2 \pm 0.1^{\mathrm{d}}$ \\
Hexenal & $0.21 \pm 0.0^{\mathrm{b}}$ & $0.26 \pm 0.0^{\mathrm{a}}$ & $0.19 \pm 0.0^{\mathrm{c}}$ & $0.18 \pm 0.0^{\mathrm{c}}$ & $0.13 \pm 0.0^{\mathrm{d}}$ & $0.11 \pm 0.0^{\mathrm{d}}$ \\
Heptenal & $1.1 \pm 0.1^{\mathrm{b}}$ & $1.6 \pm 0.1^{\mathrm{a}}$ & $1.0 \pm 0.1^{\mathrm{bc}}$ & $1.0 \pm 0.0^{\mathrm{bc}}$ & $1.0 \pm 0.1^{\mathrm{bc}}$ & $0.9 \pm 0.01^{\mathrm{c}}$ \\
Octenal & $1.0 \pm 0.1^{\mathrm{bc}}$ & $1.4 \pm 0.11^{\mathrm{a}}$ & $1.1 \pm 0.13^{\mathrm{b}}$ & $0.9 \pm 0.03^{\mathrm{c}}$ & $0.7 \pm 0.08^{\mathrm{d}}$ & $0.6 \pm 0.03^{\mathrm{e}}$ \\
Nonenal & $0.07 \pm 0.01$ & $0.07 \pm 0.02$ & $0.07 \pm 0.01$ & $0.07 \pm 0.01$ & $0.05 \pm 0.01$ & $0.05 \pm 0.01$ \\
OH-nonenal & $5.4 \pm 0.5^{\mathrm{a}}$ & $4.3 \pm 0.2^{\mathrm{b}}$ & $5.2 \pm 0.5^{\mathrm{a}}$ & $3.8 \pm 0.3^{\mathrm{c}}$ & $2.1 \pm 0.2^{\mathrm{d}}$ & $1.4 \pm 0.1^{\mathrm{e}}$ \\
\hline Total & $12.0 \pm 0.9^{\mathrm{a}}$ & $11.7 \pm 0.7^{\mathrm{a}}$ & $11.1 \pm 1.1^{\mathrm{a}}$ & $9.2 \pm 0.4^{\mathrm{b}}$ & $6.3 \pm 0.3^{\mathrm{c}}$ & $5.0 \pm 0.2^{\mathrm{d}}$ \\
\hline
\end{tabular}


Total alkenal formation was only decreased by all-rac- $\alpha$-tocopherol $(23 \%)$. With this method, BHT and Trolox showed no substantial effect. With Trolox some of the minor alkenals (pentenal - octenal) were even higher than in the control. According to the blank this is not caused by an impurity of Trolox. However Trolox lowered $\mathrm{OH}-$ nonenal, its concentration was significantly decreased by $21 \%$.

BHT is a phenolic antioxidant with two short side chains. It is less lipophilic than $\alpha$-tocopherol because it lacks the isoprenyl side chain. According to the results presented this compound seems the least appropriate one for both methods. However others reported the superiority of BHT over $\alpha$-tocopherol in a lipophilic environment (Couvelier et al., 1990).

Trolox as an analogue of the chromane ring of the all-rac- $\alpha$-tocopherol is the most hydrophilic of the antioxidants tested. It possesses a carboxyl group instead of the isoprene side chain. It is therefore suggested that the isoprenyl side chain of $\alpha$-tocopherol is important in increasing its solubility in the lipid phase of the liver homogenate. But even Trolox partitions about $40 \%$ into the lipid phase of unilamellar liposomes (Barclay et al., 1995). The autoxidizable substrates are localized in the hydrophobic cores of the membrane fragments present in the samples. This could be the reason for the higher effectiveness of all-rac- $\alpha$-tocopherol as compared to BHT and Trolox in the inhibition of TBARS and alkenal generation by atmospheric oxygen in the samples (Goetz et al., 1993).

It is concluded that tissue samples undergo a rapid decomposition of preformed lipid hydroperoxides and further autoxidation during the assay period profoundly affecting TBARS and also alkenal measurements. Both processes cannot be prevented completely by the antioxidants tested. When this is not controlled through exclusion of oxygen, the use of all-rac- $\alpha$-tocopherol $(5 \mathrm{mmol} / \mathrm{l})$ is recommended. For determination of TBARS $0.5 \mathrm{mmol} / 1$ Trolox seems to be sufficient.

\section{Acknowledgements}

The authors thank the Deutscher Akademischer Austauschdienst for supporting the study leave of Sakurani T. Balthazary in Germany.

\section{References}

Barclay, L. R. C., Artz, J. D. and Mowat, J. J. (1995): Partitioning and antioxidant action of the water-soluble antioxidant, Trolox, between the aqueous and lipid phases of phosphatidylcholine membranes: C-14 tracer and product studies. Biochim. Biophys. Acta. 1237, 77-85.

Benzie, I. F. F. (1996): Lipid peroxidation: A review of causes, consequences, measurement and dietary influences. Int. J. Food Sci. Nutr. 47, 233-261. 
Couvelier, M.-E., Berset, C. and Richard, H. (1990): Use of a new test for determining comparative antioxidative activity of butylated hydroxyanisole, butylated hydroxytoluene, alpha- and gamma-tocopherols and extracts from rosemary and sage. Sci. Aliments. 10, 797-806.

Esterbauer, H. (1993): Cytotoxicity and genotoxicity of lipid-oxidation products. Am. J. Clin. Nutr. 57, 779S-785S.

Fuhrmann, H. and Sallmann, H.-P. (1997): Unsaturated aldehydes in plasma, liver and brain of chicken in response to dietary vitamin $\mathrm{E}$ and fat type. Nutr. Res. 17, 363-378.

Goetz, M. E., Dirr, A., Freyberger, A., Burger, R. and Riederer, P. (1993): The thiobarbituric acid assay reflects susceptibility to oxygen induced lipid peroxidation in vitro rather than levels of lipid hydroperoxides in vivo: A methodological approach. Neurochem. Int. 22, 255-262.

Janero, D. R. (1990): Malondialdehyde and thiobarbituric acid-reactivity as diagnostic indices of lipid peroxidation and peroxidative tissue injury. Free Radical Biol. Med. 9, 515-540.

Tamura, H., Kitta, K. and Shibamoto, T. (1991): Formation of reactive aldehydes from fatty acids in a Fe ${ }^{2+} / \mathrm{H}_{2} \mathrm{O}_{2}$ oxidation system. J. Agric. Food Chem. 39, 439-442.

Uchiyama, M. and Mihara, M. (1978): Determination of malonaldehyde precursor in tissues by thiobarbituric acid test. Anal. Biochem. 86, 271-278. 